\title{
Solid-State Fermentation as a Strategy to Improve the Bioactive Compounds Recovery from Larrea tridentata Leaves
}

\author{
Sílvia Martins • José A. Teixeira • Solange I. Mussatto
}

Received: 21 October 2012 / Accepted: 3 April 2013 /

Published online: 19 April 2013

(C) Springer Science+Business Media New York 2013

\begin{abstract}
Chemical composition of Larrea tridentata leaves was determined and elevated content of lignin $(35.96 \% \mathrm{w} / \mathrm{w})$ was found. The present study was proposed in order to evaluate the extraction of bioactive compounds, particularly phenolic compounds, by solid-state fermentation (SSF) of L. tridentata leaves. The basidiomycete Phanerochaete chrysosporium was used in the experiments due to its ability to degrade lignin. The concentration of total phenolic compounds in the extracts produced by SSF was determined. Additionally, the extracts were characterized regarding the concentration of flavonoids, quercetin, kaempferol, and nordihydroguaiaretic acid and antioxidant activity. SSF was not an efficient process to recover phenolic compounds from $L$. tridentata leaves. However, this process was very efficient when used as a pretreatment before the plant extraction with organic solvent (methanol). By submitting the plant to SSF and subsequently to extraction with $90 \%(v / v)$ methanol, the recovery of phenolic compounds was improved by $33 \%$ when compared to the results obtained by methanolic extraction of the non-fermented plant. Scanning electron microscopy micrographs revealed a major disorganization and porosity of the plant structure after fermentation, and Fourier transform infrared spectroscopy spectra indicated a possible solubilization of some constituents of lignocellulose fraction after this process, which may have favored the solvent action in the later stage.
\end{abstract}

Keywords Antioxidant activity · Bioactive compounds - Larrea tridentata $\cdot$ Lignin · Phanerochaete chrysosporium $\cdot$ Phenolic compounds · Solid-state fermentation

\section{Introduction}

Larrea tridentata (Sesse \& Mocino ex DC.), also known as creosote bush or chaparral, is a plant belonging to the family Zygophyllaceae that grows in areas of the desert southwest in the USA and Northern Mexico, as well as in some desert areas of Argentina [1,2]. It was

S. Martins $\cdot$ J. A. Teixeira $\cdot$ S. I. Mussatto $(\bowtie)$

Institute for Biotechnology and Bioengineering (IBB), Centre of Biological Engineering,

University of Minho, Campus Gualtar, 4710-057 Braga, Portugal

e-mail: solange@deb.uminho.pt

S. I. Mussatto

e-mail: solangemussatto@hotmail.com 
traditionally used for centuries as a medicinal plant for treatment of several illnesses including infections, kidney problems, gallstones, rheumatism, arthritis, diabetes, and tumors [3]. L. tridentata is an outstanding source of natural compounds with approximately $50 \%$ of the leaves (dry weight) being extractable matter [4]. Phenolic compounds such as flavonoids, quercetin, kaempferol, and nordihydroguaiaretic acid are bioactive compounds that can be found in the composition of this plant $[2,5]$, and several studies have demonstrated their potential in the health area [6-9].

Extraction of plant-derived bioactive compounds has usually been performed by conventional extraction processes such as solid-liquid extraction using organic solvents. Recently, fermentation processes, in particular the solid-state fermentation (SSF), have become an interesting alternative technology for the production/extraction of plant bioactive compounds [10-12]. SSF is defined as fermentation involving solids in absence (or near absence) of free water; however, the substrate must possess enough moisture to support growth and metabolism of microorganisms. Different microorganisms, including fungi, yeasts, and bacteria, may be used in SSF processes; however, fungi and yeasts are the most commonly used due to their ability to grow in environments with low moisture content [10].

The white rot fungus Phanerochaete chrysosporium is a filamentous fungal strain with the ability to produce lignin and manganese peroxidases [13, 14] and is known for its potential to degrade lignin (a polyphenolic macromolecule). The biodegradation of lignin by ligninolytic enzymes is a nonspecific free radical-linked reaction that results in the destabilization of bonds and finally into breakdown of the macromolecule [15].

In the present study, the chemical composition of L. tridentata leaves was determined and elevated content of lignin was found. Based on this result, the extraction of bioactive compounds, particularly phenolic compounds, from $L$. tridentata leaves was proposed. Extraction experiments were carried out by SSF with the basidiomycete P. chrysosporium, and the ability of this fungus to recover or enhance the extraction of total phenolic compounds was evaluated. The produced extracts were also characterized in order to determine the antioxidant activity and the concentration of flavonoids, nordihydroguaiaretic acid, quercetin, and kaempferol. Scanning electron microscopy micrographs (SEM) micrographs and Fourier transform infrared spectroscopy (FTIR) analyses of the fermented plant material were carried out to explain the modifications that occurred in the plant structure during SSF.

\section{Materials and Methods}

\section{Plant Material and Chemicals}

L. tridentata was collected in the Chihuahuan Semidesert (North Coahuila, Mexico) during spring season (April 2009). Nordihydroguaiaretic acid (NDGA), quercetin, kaempferol, 2,2diphenyl-1-picrylhydrazyl, 2,4,6-tris (1-pyridyl)-5-triazine, sodium acetate, aluminum chloride, ferrous sulfate, and iron(III) chloride were purchased from Sigma-Aldrich (Saint Louis, MO, USA). Reagent-grade methanol, ethanol, acetone, acetic acid, and Folin-Ciocalteu were from Panreac (Barcelona, Spain). Potassium acetate was from AppliChem (Darmstadt, Germany). High-performance liquid chromatography (HPLC)-grade acetonitrile was purchased from Fisher Scientific (Leicestershire, UK). Ultrapure water from a Milli-Q System (Millipore Inc., USA) was used. 


\section{Chemical Characterization of L. tridentata}

Chemical composition of L. tridentata leaves was determined according to standard procedures [16]. Briefly, the plant material was subjected to a quantitative acid hydrolysis with $72 \%(w / w) \mathrm{H}_{2} \mathrm{SO}_{4}$ at $45{ }^{\circ} \mathrm{C}$ during 7 min. Afterwards, distilled water was added to the mixture to dilute the $\mathrm{H}_{2} \mathrm{SO}_{4}$ to $1 \mathrm{~N}$, and the samples were autoclaved at $121{ }^{\circ} \mathrm{C}$ for $45 \mathrm{~min}$. The solid residue after hydrolysis was recovered by filtration and considered as Klason lignin (after subtracting the content of ashes). The monosaccharides and acetic acid contained in the hydrolysates were determined by HPLC in order to estimate (after corrections for stoichiometry and sugar decomposition) the contents of samples in cellulose (as glucan), hemicellulose (xylan, arabinan, galactan, and mannan) and acetyl groups [17]. To determine the amount of acid-soluble lignin, hydrolysate samples had their $\mathrm{pH}$ adjusted to 12 by addition of $\mathrm{NaOH} 6 \mathrm{M}$. Then, the $\mathrm{pH}$-adjusted samples were diluted with distilled water and analyzed in a spectrophotometer at $280 \mathrm{~nm}$. Hydrolysate samples were also analyzed by HPLC in order to quantify the amounts of furfural and hydroxymethylfurfural, which were used to calculate the percentage of acid-soluble lignin. Glucose, xylose, arabinose, mannose, galactose, furfural, and hydroxymethylfurfural were determined by HPLC [18].

To quantify the content of ashes, $1 \mathrm{~g}$ of the ground air-dried plant material, accurately weighed, was placed in a previously ignited and tared crucible and heated at $550{ }^{\circ} \mathrm{C}$ for $4 \mathrm{~h}$. The content of total ashes was calculated by the difference of weight before and after incineration of the sample. The protein content was determined by quantification of the total nitrogen using the Kjeldahl method. A conversion factor of 6.25 was used. The extractives were calculated by difference, i.e., by subtracting the sum of cellulose, hemicelluloses, total lignin, ashes, proteins, and acetyl groups, from the dry weight of the plant sample.

Organic carbon and total nitrogen contents were determined by combustion using a Thermo Scientific Flash 2000 Elemental Analyzer. The mineral content was determined by inductively coupled plasma atomic emission spectrometry (ICP-AES). Samples $\left(200 \mathrm{mg}\right.$ ) were digested with $\mathrm{HNO}_{3}(5 \mathrm{~mL})$ and $\mathrm{H}_{2} \mathrm{O}_{2}(3 \mathrm{~mL})$ in closed vessels (XF100, Anton Paar) using a Multiwave 3000 microwave (Anton Paar). For the digestion, the microwave power was increased from 0 to $1,150 \mathrm{~W}$ during 9 min and was then maintained at $1,150 \mathrm{~W}$ during $10 \mathrm{~min}$. After cooled to room temperature, the final volume of the samples was adjusted to $100 \mathrm{~mL}$, and they were analyzed by ICP-AES in a Thermo Scientific iCAP 6300 equipment.

\section{SSF Process}

\section{Fungal Strain and Spore Collection}

P. chrysosporium MUM 9415 (from Micoteca of the Centre of Biological Engineering, University of Minho) was the fungus used in the experiments. The strain was maintained at $4{ }^{\circ} \mathrm{C}$ on Petri plates containing potato dextrose agar (PDA, Difco). For the production of spores, the cultures were maintained at $37{ }^{\circ} \mathrm{C}$ on fresh PDA medium for 7 days. The inoculum for use in the experiments was obtained by suspension of the produced spores in sterilized solution of $0.1 \%(w / v)$ Tween 80 and adjustment to the desired concentration by counting in a Neubauer chamber. 


\section{SSF Conditions}

Figure 1 is a schematic representation of the experimental steps used for SSF of L. tridentata leaves. SSF cultivations were performed in 250-mL Erlenmeyer flasks containing $10 \mathrm{~g}$ of sterilized powdered plant. The plant material was moistened with the following culture medium in order to attain $70 \%$ moisture content (in grams per liter): $\mathrm{K}_{2} \mathrm{HPO}_{4}(1.0), \mathrm{NaNO}_{3}$ (3.0), $\mathrm{MgSO}_{4}(0.5), \mathrm{FeSO}_{4} \cdot 7 \mathrm{H}_{2} \mathrm{O}(0.01)$, and $\mathrm{KCl}(0.5)$, adjusted to $\mathrm{pH}$ 5.0, and sterilized at $121{ }^{\circ} \mathrm{C}$ for $15 \mathrm{~min}$. The moistened material was inoculated with $2 \times 10^{7}$ spores/g dry weight (wt) plant and statically incubated at $37^{\circ} \mathrm{C}$. Samples for analysis were collected after 7,10 , 14,18 , and 21 days of cultivation. The moisture of the fermentation media was regularly checked every 3 days and adjusted to $70 \%$ by the addition of sterilized culture medium. The total content of each Erlenmeyer flask was taken as a sample. The fermented broth was filtered through $0.2-\mu \mathrm{m}$ membrane filters and stored at $-20{ }^{\circ} \mathrm{C}$ until further analysis. The fermented plant was dried at $30{ }^{\circ} \mathrm{C}$ to approximately $10 \%$ moisture content and then subjected to extraction with $90 \%(\mathrm{v} / \mathrm{v})$ methanol ( $1 \mathrm{~g}$ of fermented plant to $20 \mathrm{~mL}$ methanol) during $30 \mathrm{~min}$ in a water bath at $65-70{ }^{\circ} \mathrm{C}$. The produced extracts (methanolic extracts) were filtered through $0.2 \mu \mathrm{m}$ membrane filters and stored at $-20{ }^{\circ} \mathrm{C}$ for further analyses.

The fermented broth and the methanolic extracts were characterized regarding the antioxidant activity and concentrations of total phenolic compounds, flavonoids, quercetin, kaempferol, and NDGA. The fermented plant material was subjected to FTIR and SEM

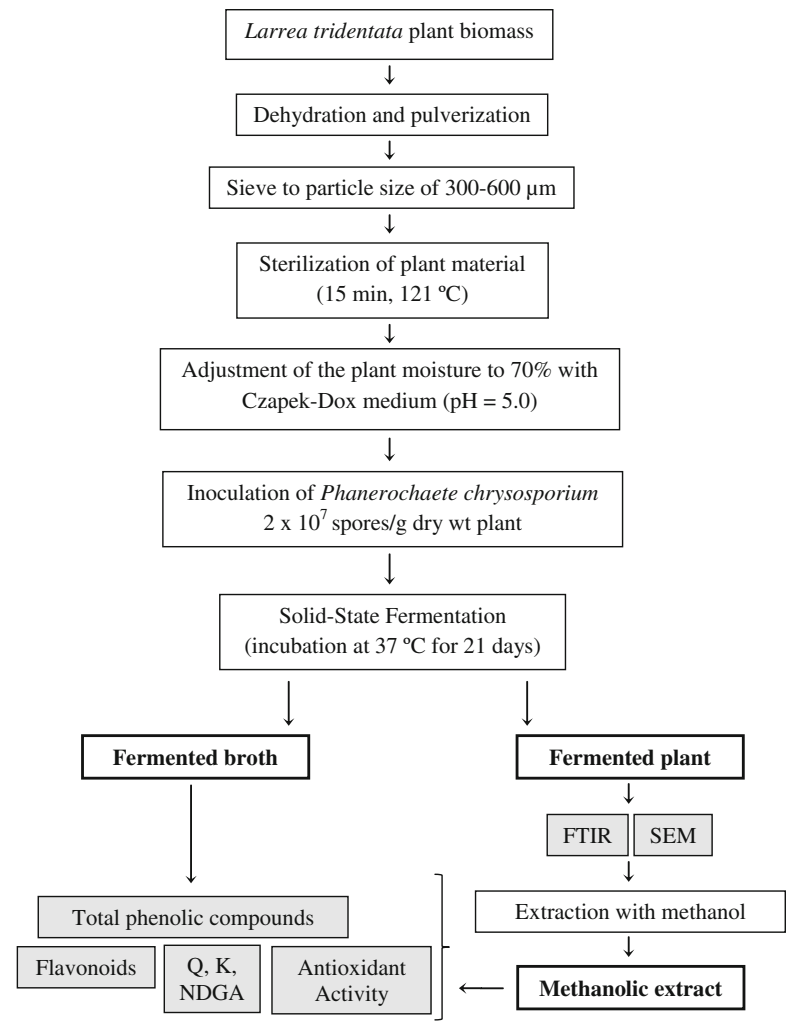

Fig. 1 Schematic representation of the experimental steps used to recover phenolic compounds by solid-state fermentation of $L$. tridentata leaves. Quercetin $(Q)$, kaempferol $(K)$, nordihydroguaiaretic acid $(N D G A)$ 
analyses. All the experimental assays and determinations were performed in triplicate, and mean values are presented.

\section{Analytical Procedures}

Total phenolic compounds were determined by the Folin-Ciocalteu method modified for use in a 96-well microplate. Briefly, $5 \mu \mathrm{L}$ of the filtered and duly diluted extracts was mixed with $60 \mu \mathrm{L}$ of sodium carbonate solution $(7.5 \% \mathrm{w} / v)$ and $15 \mu \mathrm{L}$ of Folin-Ciocalteu reagent in a 96-well microplate. Then, $200 \mu \mathrm{L}$ of distilled water was added and the solutions were mixed. After standing for $5 \mathrm{~min}$ at $60{ }^{\circ} \mathrm{C}$, the samples were allowed to cool at room temperature. The absorbance was measured using a spectrophotometric microplate reader (Sunrise Tecan, Grödig, Austria) set at $700 \mathrm{~nm}$. A calibration curve was prepared using a standard solution of gallic acid $\left(200,400,600,800,1,000,2,000\right.$, and 3,000 mg/L; $R^{2}=$ 0.9987). The total content of phenolic compounds was expressed as milligram gallic acid equivalent per dry weight of plant material (mg GAE/g dry wt plant).

Flavonoids were quantified by colorimetric assay. Briefly, $30 \mu \mathrm{L}$ of the diluted and filtered extracts was added to $90 \mu \mathrm{L}$ of methanol in a 96-well microplate. Subsequently, $6 \mu \mathrm{L}$ of aluminum chloride $(10 \% \mathrm{w} / \mathrm{v}), 6 \mu \mathrm{L}$ of potassium acetate $(1 \mathrm{~mol} / \mathrm{L})$, and $170 \mu \mathrm{L}$ of distilled water were sequentially added to the mixture, which was maintained during $30 \mathrm{~min}$ in the dark at room temperature. The absorbance of the mixture was then read at $415 \mathrm{~nm}$ against a blank prepared with distilled water, using a spectrophotometric microplate reader (Sunrise Tecan, Grödig, Austria). A calibration curve was prepared using a standard solution of quercetin $\left(25,50,100,150\right.$, and $\left.200 \mathrm{mg} / \mathrm{L} ; R^{2}=0.9994\right)$. The content of flavonoids was expressed as milligram quercetin equivalent per dry weight of plant material (mg QE/g dry wt plant).

NDGA, kaempferol, and quercetin concentrations were determined by HPLC on an LC-10 A equipment (Jasco, Japan) with a $\mathrm{C}_{18} 5 \mu \mathrm{m}(3.9 \times 300 \mathrm{~mm})$ column at room temperature and a UV detector at $280 \mathrm{~nm}$. The response of the detector was recorded and integrated using the Star Chromatography Workstation software (Varian). The mobile phase consisted of acetonitrile (solvent $\mathrm{A}$ ) and $0.3 \%$ acetic acid in water $(v / v)$ (solvent $\mathrm{B}$ ) under the following gradient profile: $30 \% \mathrm{~A} / 70 \% \mathrm{~B}(0-2 \mathrm{~min}), 50 \% \mathrm{~A} / 50 \% \mathrm{~B}(2-11 \mathrm{~min}), 70 \% \mathrm{~A} / 30 \% \mathrm{~B}(11-17 \mathrm{~min}), 100 \% \mathrm{~A}$ $(17-22 \mathrm{~min})$, and $30 \% \mathrm{~A} / 70 \% \mathrm{~B}(22-40 \mathrm{~min})$. The mobile phase was eluted in a flow rate of $1.0 \mathrm{~mL} / \mathrm{min}$, and samples of $10 \mu \mathrm{L}$ were injected. Prior to the analysis, all the extracts were filtered through 0.2- $\mu \mathrm{m}$ membrane filters. NDGA, kaempferol, and quercetin contents in the extracts were expressed as the ratio between the mass of the compound in the extracts and mass of plant material (in milligrams per gram dry wt plant).

The antioxidant activity of the extracts was determined according to Prieto et al. [19]. An aliquot of $0.1 \mathrm{~mL}$ of sample was mixed in a tube with $1 \mathrm{~mL}$ of a reagent solution containing $0.6 \mathrm{M}$ sulfuric acid, $28 \mathrm{mM}$ sodium phosphate, and $4 \mathrm{mM}$ ammonium molybdate. The tubes were closed with lids and incubated in a water bath at $95{ }^{\circ} \mathrm{C}$ for $90 \mathrm{~min}$. After the samples had cooled to room temperature, the absorbance was measured at $695 \mathrm{~nm}$ against a blank that contained $1 \mathrm{~mL}$ of reagent solution and $0.1 \mathrm{~mL}$ of the same solvent present in the sample (water or methanol). The blank was incubated under the same conditions used for the other samples. A calibration curve was prepared using a standard solution of $\alpha$-tocopherol $(25,75$, $125,250,375$, and $\left.500 \mu \mathrm{g} / \mathrm{mL} ; R^{2}=0.9961\right)$. The total antioxidant capacity of the samples was expressed as equivalents of $\alpha$-tocopherol/g dry wt plant material.

FTIR analyses were carried out in a Jasco infrared spectrometer (FT/IR-4100 Type A) using a frequency range from 4,000 to $500 \mathrm{~cm}^{-1}$. For FTIR measurement, the dried plant samples were mixed with spectroscopic grade $\mathrm{KBr}$ and then pressed using a hydraulic 
pressing system at $10 \mathrm{t}$ to form pellets of about $10 \mathrm{~mm}$ in diameter and $1 \mathrm{~mm}$ in thickness. The vibration transition frequencies of the spectra were subjected to baseline correction.

Micrographs of plant material samples were obtained by SEM using a Leica Cambridge S360 microscope. For the analyses, the samples were fixed on a specimen holder with aluminum tape and then sputtered with gold in a sputter coater under high vacuum condition. Images were obtained at 200- and 1,000-fold magnifications.

\section{Results and Discussion}

\section{Chemical Characterization of L. tridentata Leaves}

Chemical characterization analyses revealed that L. tridentata leaves are composed of $2.27 \%$ $(w / w)$ total nitrogen and $46.30 \%(w / w)$ organic carbon (Table 1$)$. Carbon is mainly distributed in the fractions of cellulose, hemicellulose, and lignin. Cellulose and hemicellulose are fractions basically composed of sugars, which include glucose (in cellulose), xylose, arabinose, galactose, and mannose (in hemicellulose). Lignin is the most abundant fraction in the composition of this plant $(35.96 \% \mathrm{w} / \mathrm{w})$. The lignin content in L. tridentata leaves is still greater than the sum of the fractions containing sugars, namely cellulose $(10.09 \% \mathrm{w} / \mathrm{w})$ and hemicellulose $(13.10 \%$ $w / w)$, revealing the importance of this fraction in the constitution of the plant. Lignin is a polyphenolic macromolecule closely bound to cellulose and hemicellulose in cell walls of plants, conferring water impermeability of xylem vessels and forming a physical-chemical barrier against microbial attack [20]. Due to its complex and heterogeneous structure, lignin is extremely difficult to be chemically degraded [21]. The high content of lignin in L. tridentata leaves makes this plant a challenging raw material to obtain phenolic compounds. Some phenolic compounds with important biological functions, including flavonoids, kaempferol, quercetin, and NDGA, have been reported to be present in the composition of this plant $[2,5]$.

Table 1 Chemical composition of Larrea tridentata leaves

\begin{tabular}{ll}
\hline Component/Fraction & $\%$ dry weight $(\mathrm{g} / 100 \mathrm{~g})$ \\
\hline Elemental component & \\
Carbon & 46.30 \\
Nitrogen & 2.27 \\
Fraction & \\
Cellulose (glucan) & 10.09 \\
Hemicellulose & 13.10 \\
Xylan & 4.42 \\
Arabinan & 4.68 \\
Galactan & 2.05 \\
Mannan & 1.95 \\
Total lignin & 35.96 \\
Klason lignin & 31.06 \\
Acid-soluble lignin & 4.90 \\
Ashes & 7.91 \\
Protein & 13.01 \\
Acetyl groups & 2.62 \\
Extractives & 17.31 \\
\hline
\end{tabular}


Chemical analyses revealed also the presence of important fractions of extractives, protein, and ashes in L. tridentata leaves (Table 1). Mineral elements present in the ashes are listed in Table 2. Among them, calcium, potassium, sulfur, magnesium, phosphorus, boron, iron, manganese, zinc, copper, molybdenum, and nickel are considered mineral elements essential for plant growth. Some beneficial elements able to promote growth in many plant species but that are not absolutely necessary for completion of the plant life cycle were also found in the composition of this plant, including aluminum, sodium, cobalt, and selenium [22]. Besides the essential and beneficial minerals, other elements, in particular, barium, strontium, tin, iodine, and gallium, were also found in L. tridentata leaves.

\section{Effect of SSF in the Plant Material Structure}

FTIR and SEM analyses have been extensively used to investigate the structure of plant materials. FTIR spectroscopy is considered a powerful and rapid assay for the determination of cell wall components and putative cross-links, by identifying functional groups nondestructively [23]. In the present study, FTIR spectra of L. tridentata samples before and after 21 days of SSF were obtained in order to verify if the SSF process caused modifications in the plant structure. In these spectra (Fig. 2), a strong hydrogen bonded $(\mathrm{O}-\mathrm{H})$ stretching absorption was observed at $3,400 \mathrm{~cm}^{-1}$ and a $(\mathrm{C}-\mathrm{H})$ stretching absorption around

Table 2 Mineral elements in Larrea tridentata leaves

\begin{tabular}{ll}
\hline Mineral element & $\%$ dry weight $(\mathrm{g} / 100 \mathrm{~g})$ \\
\hline Calcium & 2.27 \\
Potassium & 1.11 \\
Sulfur & 0.39 \\
Magnesium & 0.14 \\
Phosphorus & 0.10 \\
& $(\mathrm{mg} / \mathrm{kg})$ \\
Sodium & 593.0 \\
Iron & 304.8 \\
Aluminum & 275.1 \\
Strontium & 109.3 \\
Boron & 52.3 \\
Iodine & 51.5 \\
Manganese & 41.0 \\
Zinc & 23.9 \\
Barium & 18.4 \\
Copper & 5.8 \\
Nickel & 1.2 \\
Vanadium & 1.1 \\
Molybdenum & 1.0 \\
Selenium & $<1.6$ \\
Gallium & $<1.5$ \\
Tin & $<1.3$ \\
Cobalt & $<0.6$ \\
Chromium & $<0.5$ \\
\hline &
\end{tabular}




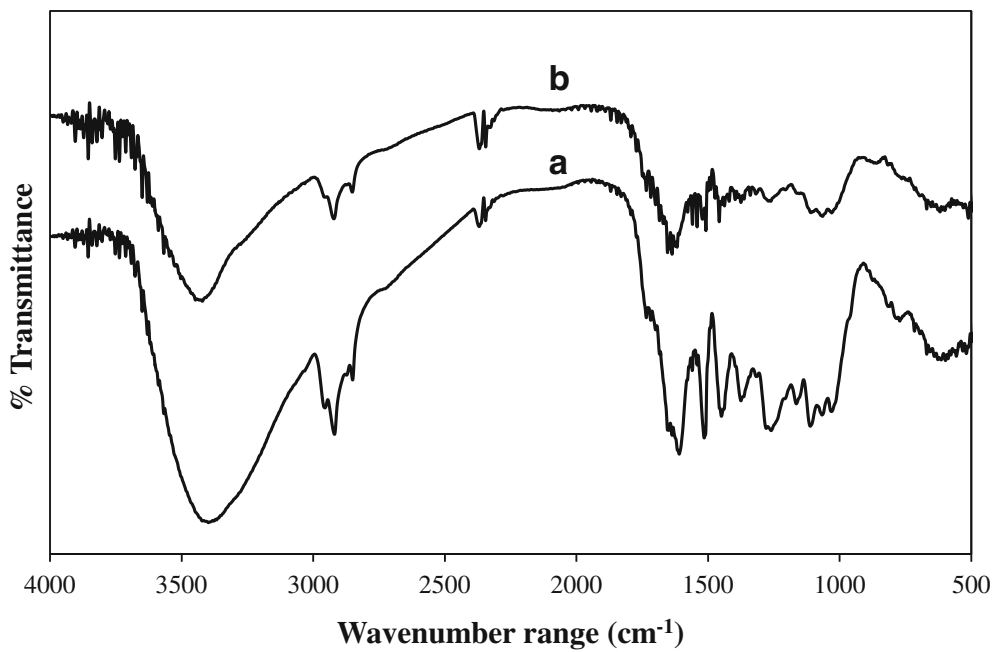

Fig. 2 FTIR spectra of L. tridentata samples before (a) and after 21 days of solid-state fermentation (b) with P. chrysosporium

$2,960 \mathrm{~cm}^{-1}$ was also detected. There were also many well-defined peaks in the finger print region between 1,800 and $600 \mathrm{~cm}^{-1}$, being assigned as follows: $1,640 \mathrm{~cm}^{-1}$ for absorbed $\mathrm{O}-\mathrm{H}$ and conjugated $\mathrm{C}-\mathrm{O}, 1,460$ and $1,440 \mathrm{~cm}^{-1}$ for $\mathrm{C}-\mathrm{H}$ deformation in lignin, $1,380 \mathrm{~cm}^{-1}$ for $\mathrm{C}-\mathrm{H}$ deformation in cellulose and hemicellulose, $1,320 \mathrm{~cm}^{-1}$ for $\mathrm{C}-\mathrm{H}$ vibration in cellulose and $\mathrm{C}-\mathrm{O}$ vibration in syringyl derivatives, and $1,100 \mathrm{~cm}^{-1}$ for aromatic skeletal and $\mathrm{C}-\mathrm{O}$ stretch in cellulose and hemicellulose [24-28]. When comparing the FTIR spectra of the plant samples before (Fig. 2a) and after 21 days of SSF (Fig. 2b), it can be noted that the intensities of the absorption bands decreased after fermentation, suggesting some solubilization of constituents of the lignocellulose fraction.

SEM analyses were carried out to verify possible morphological changes in the plant matrix after SSF (Fig. 3). The obtained micrographs revealed a distinct organization in the plant structure before (Fig. 3a, b) and after fungal cultivation during 21 days (Fig. 3c, d). In the latter case, a major disorganization and porosity of the material structure was observed, revealing that the fungal strain was able to attack the plant material. These results are in agreement with those obtained by FTIR analysis, which suggested solubilization of some cell wall components during the SSF process. As a consequence, the structure of the plant material became more porous, and the fibers were separated from the initial rigid structure that presented closed cells. Figure $3 \mathrm{~d}$ revealed also the presence of porous with different sizes in the plant structure after the fungal attack.

\section{Phenolic Compound Extraction by SSF}

P. chrysosporium is a white rot fungus known by its ability to produce extracellular oxidative enzymes, in particular lignin and manganese peroxidases, which degrade polyphenolic structures such as lignin $[13,14]$. Therefore, it was selected to be used in the present study with the objective of extracting phenolic compounds from L. tridentata leaves. Figure 4a shows the concentration of total phenolic compounds in the extracts produced by SSF. Samples were withdrawn after 7, 10, 14, 18, and 21 days of fermentation; however, samples collected after 10 and 14 days presented similar composition and were then 

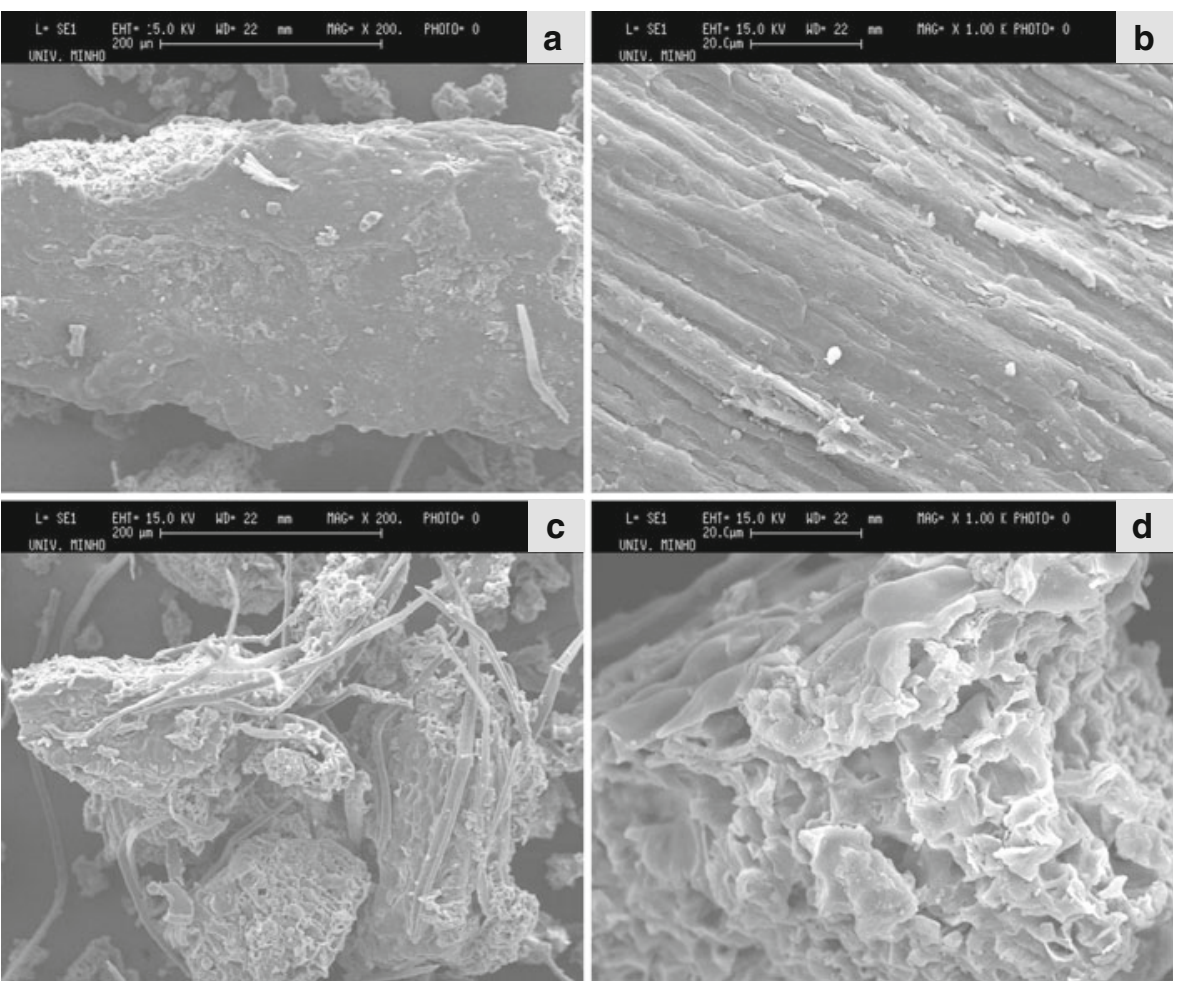

Fig. 3 Micrographs by scanning electron microscopy of L. tridentata samples in the following forms: $(\mathbf{a}, \mathbf{b})$ before and (c, d) after 21 days of solid-state fermentation with P. chrysosporium. Magnification, 200-fold (a, c) and 1,000 -fold $(\mathbf{b}, \mathbf{d})$

presented as an average value in this figure. The same fact was observed for the samples collected after 18 and 21 days of SSF.

Although SSF has been demonstrated to be a very efficient process to extract phenolic compounds from other natural resources [29-31], SSF with P. chrysosporium was not an efficient process to extract phenolic compounds from $L$. tridentata leaves (Fig. 4a). The highest concentration of phenolic compounds (70.4 mg GAE/g dry wt plant) was obtained after 7 days of fermentation, but this value was much lower than that obtained by direct extraction of the non-fermented plant with methanol (263.6 mg GAE/g dry wt plant), as reported in a previous study [5]. However, more elevated concentrations of phenolic compounds were recovered after extraction of the fermented plant material with methanol. In this case, $280.8 \mathrm{mg} \mathrm{GAE} / \mathrm{g}$ dry wt plant was recovered from the plant fermented during 7 days, which is a value higher than that recovered by solvent extraction only $(263.6 \mathrm{mg}$ GAE/g dry wt plant; Fig. 4a). These results reveal that SSF enhanced the recovery of phenolic compounds from $L$. tridentata, since the total concentration of phenolic compounds recovered from the plant material (351.2 $\mathrm{mg}$ GAE/g dry wt plant) was improved by $33 \%$ by using SSF followed by solvent extraction than when extracting the non-fermented plant. These values are in agreement with the FTIR and SEM analyses of the fermented plant material, which revealed a major disorganization of the plant structure with possible solubilization of some of its constituents that may have favored the solvent action in the subsequent stage. The highly porous structure of the plant material after SSF (Fig. 3d) 

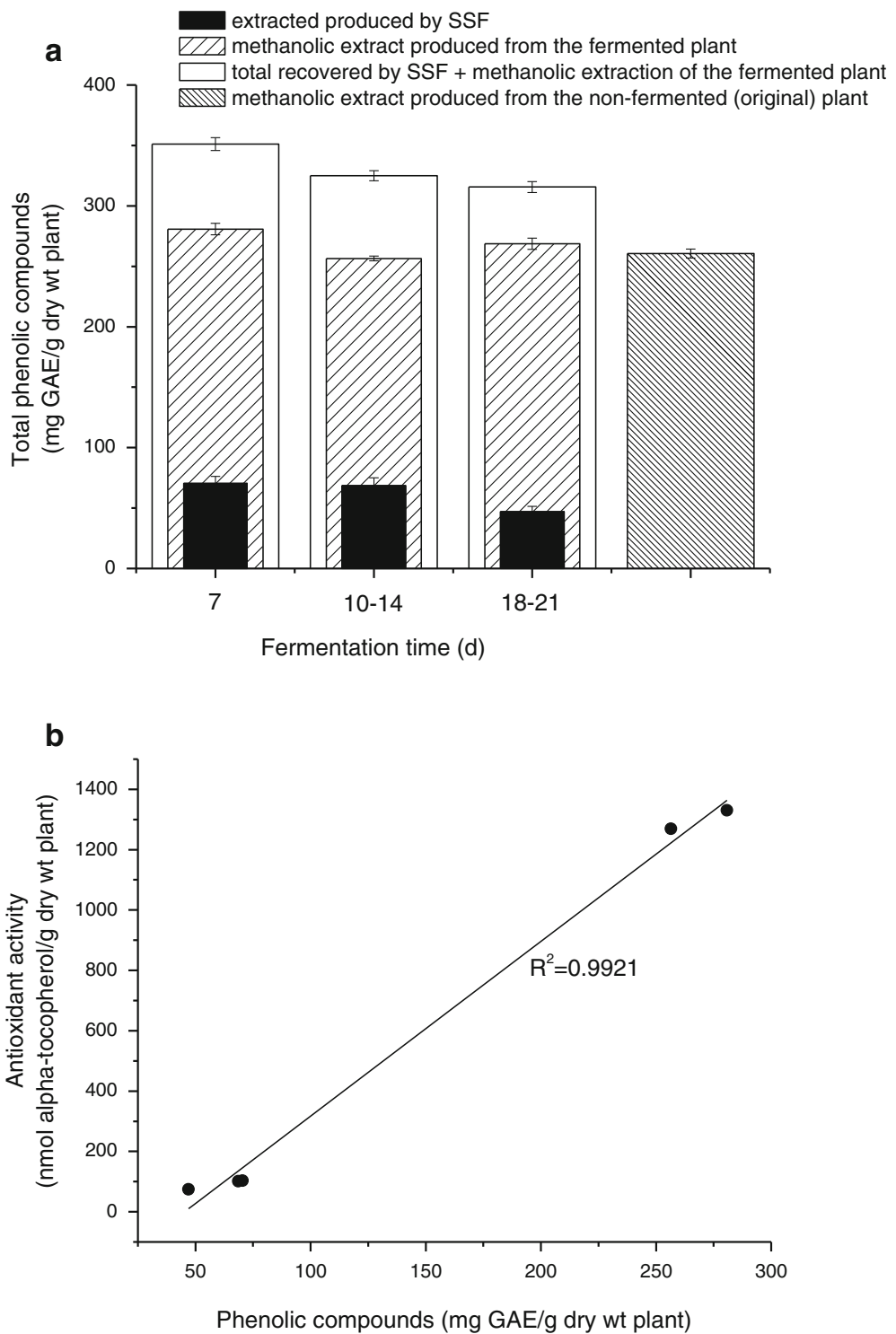

Fig. 4 Concentration of total phenolic compounds in the extracts obtained by solid-state fermentation (SSF) of L. tridentata leaves and in the extracts produced by methanolic extraction of the fermented plant material (a). Correlation between concentration of total phenolic compounds and antioxidant activity of the extracts produced from L. tridentata leaves (b)

probably allowed a better penetration of the solvent into the cell wall structure, which made possible to increase the extraction of phenolic compounds.

An integrated system consisting of 7 days of SSF at $37^{\circ} \mathrm{C}$ followed by $30 \mathrm{~min}$ methanolic extraction $65-70{ }^{\circ} \mathrm{C}$ was then demonstrated to be more efficient to recover phenolic compounds from L. tridentata than methanolic extraction only. Although the time needed to recover these compounds was significantly increased when performing the SSF before the 
solvent extraction, considering the economic value and number of industrial applications of the phenolic compounds, the $33 \%$ increase on the recovery of these compounds is expected to justify the lower productivity provided by this integrated system. Additionally, SSF does not require elevated energy expenses since this process was performed under static conditions and low temperature $\left(37^{\circ} \mathrm{C}\right)$.

All the extracts produced from L. tridentata leaves presented antioxidant activity, which exhibited strong correlation $\left(R^{2}=0.9921\right)$ with the concentration of phenolic compounds present in the sample (Fig. 4b). Additionally, all the extracts contained flavonoids, quercetin, kaempferol, and NDGA in the composition that is in agreement with other studies $[2,4,5]$.

Similar to the total phenolic compounds, the extraction of quercetin, kaempferol, NDGA, and flavonoids from $L$. tridentata was also improved when using SSF followed by solvent extraction (Fig. 5a-d). However, except for the flavonoids (Fig. 5d), the maximum concentration of these compounds extracted from the plant material was not higher than the values previously reported for methanolic extraction of the non-fermented plant material [5]. It is
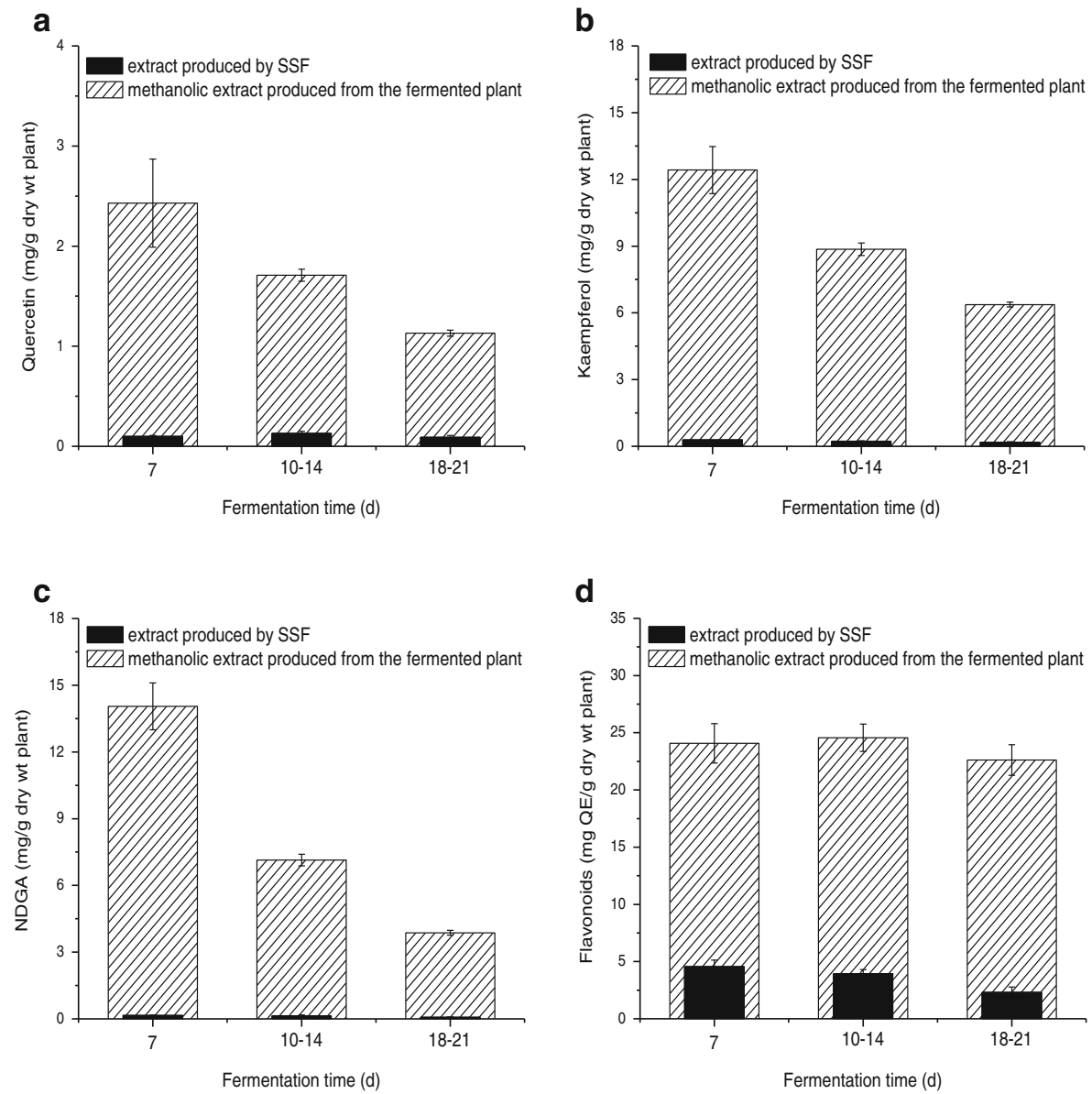

Fig. 5 Concentration of quercetin (a), kaempferol (b), nordihydroguaiaretic acid, NDGA (c), and flavonoids (d) in the extracts obtained by solid-state fermentation $(S S F)$ of L. tridentata leaves and in the extracts produced by methanolic extraction of the fermented plant material 
possible that the extraction of these compounds had been maxima in the conditions used for solvent extraction in the previous and in the present study, and therefore, the results were not improved. Otherwise, the extraction of flavonoids was improved by $32 \%$ when the plant material was treated by SSF before solvent extraction. These results clearly demonstrate that each phenolic compound is differently affected by the conditions used for extraction. Figure 5 also shows that the concentration of quercetin, kaempferol, and NDGA in the extracts decreased the longer the fermentation time, suggesting some instability of these compounds in the conditions used for fermentation. The same behavior was not observed for the flavonoids, which were in similar concentrations in the extracts produced at different fermentation times.

\section{Conclusion}

High lignin content (approximately $36 \% \mathrm{w} / \mathrm{w}$ ) was found in L. tridentata leaves and a hypothesis was formulated considering that $P$. chrysosporium, a fungal strain known to produce ligninolytic enzymes, could liberate bioactive compounds from cellular degradation of this plant material during SSF. Although some modifications were observed in the plant structure, SSF with $P$. chrysosporium was not an efficient process to extract phenolic compounds from L. tridentata leaves. However, this process was demonstrated to be efficient as a pretreatment stage before the plant extraction with methanol. When compared to the results obtained in our previous study, the use of SSF previous the extraction with methanol was able to improve by $33 \%$ the recovery of total phenolic compounds from this plant material. Additionally, the extracts presented antioxidant activity, which was strongly correlated to the concentration of phenolic compounds present. This study represents an important advance on the recovery of bioactive molecules from $L$. tridentata leaves. Our next studies will be focused on evaluating other biological activities of the produced extracts with the objective of finding future applications on the pharmaceutical area.

Acknowledgments This work was supported by FCT (contract/grant numbers: SFRH/BD/40439/2007 and SFRH/BPD/38212/2007).

\section{References}

1. Ross, I. A. (2005). Medicinal plants of the world-chemical constituents, traditional and modern medicinal uses (Vol. 3). New Jersey: Humana.

2. Abou-Gazar, H., Bedir, E., Takamatsu, S., Ferreira, D., \& Khan, I. A. (2004). Phytochemistry, 65, $2499-$ 2505.

3. Navarro, V., Villarreal, M. L., Rojas, G., \& Lozoy, X. (1996). Journal of Ethnopharmacology, 53, 143147.

4. Arteaga, S., Andrade-Cetto, A., \& Cárdenas, R. (2005). Journal of Ethnopharmacology, 98, 231-239.

5. Martins, S., Aguilar, C. N., Teixeira, J. A., \& Mussatto, S. I. (2012). Separation and Purification Technology, 88, 163-167.

6. Nakamura, Y., Chang, C.-C., Mori, T., Sato, K., Ohtsuki, K., Upham, B. L., \& Trosko, J. E. (2005). Carcinogenesis, 26, 665-671.

7. Zavodovskaya, M., Campbell, M. J., Maddux, B. A., Shiry, L., Allan, G., Hodges, L., Kushner, P., Kerner, J. A., Youngren, J. F., \& Goldfine, I. D. (2008). Journal of Cellular Biochemistry, 103, 624-635.

8. Chen, C., Zhou, J., \& Ji, C. (2010). Life Sciences, 87, 333-338.

9. Tapas, A. R., Sakarkar, D. M., \& Kakde, R. B. (2008). Tropical Journal of Pharmaceutical Research, 7 , 1088-1099. 
10. Martins, S., Mussatto, S. I., Martínez-Avila, G., Montañez-Saenz, J., Aguilar, C. N., \& Teixeira, J. A. (2011). Biotechnology Advances, 29, 365-373.

11. Pandey, A. (2003). Biochemical Engineering Journal, 13, 81-84.

12. Holker, U., \& Lenz, J. (2005). Current Opinion in Microbiology, 8, 301-306.

13. Fujian, X., Hongzhang, C., \& Vuohu, L. (2001). Bioresource Technology, 80, 149-151.

14. Kumar, A. G., Sekaran, G., \& Krishnamoorthy, S. (2006). Bioresource Technology, 97, 1521-1528.

15. Barr, D. P., \& Aust, S. D. (1994). Reviews of Environmental Contamination and Toxicology, 138, 49-72.

16. Browning, B. L. (1967). Methods of wood chemistry. New York: Wiley.

17. Irick, T. J., West, K., Brownell, H. H., Schwald, W., \& Saddler, J. N. (1988). Applied Biochemistry and Biotechnology, 17, 137-149.

18. Mussatto, S. I., Carneiro, L. M., Silva, J. P. A., Roberto, I. C., \& Teixeira, J. A. (2011). Carbohydrate Polymers, 83, 368-374.

19. Prieto, P., Pineda, M., \& Aguilar, M. (1999). Analytical Biochemistry, 269, 337-341.

20. Fengel, D., \& Wegener, G. (1989). Wood: Chemistry, ultrastructure, reactions. New York: Walter de Gruyter.

21. Martin, H. (2002). Enzyme and Microbial Technology, 30, 454-466.

22. Pilon-Smits, E. A. H., Quinn, C. F., Tapken, W., Malagoli, M., \& Schiavon, M. (2009). Current Opinion in Plant Biology, 12, 267-274.

23. Abidi, N., Cabrales, L., \& Haigler, C. N. (2013). Carbohydrate Polymers. doi:10.1016/j.carbpol.2013.01.074.

24. Hergert, H. L. (1971). In K. V. Sarkanen \& C. H. Ludwig (Eds.), Lignins. Occurrence, formation, structure and reactions (pp. 267-297). New York: Wiley.

25. Schultz, T. P., \& Glasser, W. G. (1986). Holzforschung, 40, 37-44.

26. Faix, O. (1992). In S. Y. Lin \& C. W. Dence (Eds.), Methods in lignin chemistry (pp. 83-109). Berlin: Springer.

27. Collier, W. E., Schultz, T. P., \& Kalasinsky, V. F. (1992). Holzforschung, 46, 523-528.

28. Pandey, K. K., \& Theagarajan, K. S. (1997). Holz als Roh- und Werkstoff, 55, 383-390.

29. Machado, E. M. S., Rodriguez-Jasso, R. M., Teixeira, J. A., \& Mussatto, S. I. (2012). Biochemical Engineering Journal, 60, 87-90.

30. Robledo, A., Aguilera-Carbó, A., Rodríguez, R., Martinez, J. L., Garza, Y., \& Aguilar, C. N. (2008). Journal of Industrial Microbiology and Biotechnology, 35, 507-513.

31. Zheng, Z., \& Shetty, K. (2000). Journal of Agricultural and Food Chemistry, 48, 895-900. 